\title{
A SUSTENTABILIDADE SOCIAL COMO PARÂMETRO DE SOLUÇÃO DE CONFLITOS ENTRE DIREITOS NAS CIDADES
}

\begin{abstract}
Alan Felipe Provin ${ }^{1}$
RESUMO: O presente estudo tem como objetivo evidenciar a sustentabilidade social como parâmetro de solução de conflitos entre direitos fundamentais nas cidades, em busca de um ideal sustentável, minimizando as desigualdades. Considerando que as cidades são aglutinadoras de conflitos, e os métodos tradicionais de solução de conflitos ignoram o lado social dos direitos, justifica-se a presente pesquisa pela possibilidade de contribuição aos estudos de solução de impasses fundamentais sob um novo olhar: o da sustentabilidade social. Concluiu-se pela possibilidade de aplicação desse instituto, em conjunto com o arcabouço normativo existente, fazendo-se uso de pesquisa bibliográfica e método indutivo.
\end{abstract}

Palavras-chave: Sustentabilidade social; cidades; direitos fundamentais; conflitos; desenvolvimento sustentável.

\section{SOCIAL SUSTAINABILITY AS A PARAMETER OF CONFLICT RESOLUTION BETWEEN RIGHTS IN CITIES}

\begin{abstract}
The present study aims to highlight social sustainability as a parameter for resolving conflicts between fundamental rights in the cities, in search of a sustainable ideal, minimizing inequalities. Considering that cities are agglutinating conflicts, and traditional methods of conflict resolution ignore the social side of rights, this research is justified by the possibility of contributing to studies of solving fundamental impasses under a new look: that of social sustainability. It was concluded by the possibility of application of this institute, together with the existing normative framework, making use of bibliographic research and inductive method.
\end{abstract}

Keywords: Social sustainability; cities; fundamental rights; conflicts; sustainable development.

\section{INTRODUÇÃO}

Vive-se em um mundo de conflitos. Os conflitos, que pairam tanto no mundo teóricoquanto material, tornaram-se rotina.

Da mesma forma, a exclusão social e a degradação do meio ambiente em busca daexpansão econômica foram naturalizadas.

\footnotetext{
${ }^{1}$ Registrador. Professor. Graduado em Direito, Mestre e Doutorando em Ciência Jurídica pela Universidade do Vale do Itajaí (UNIVALI), em cujo programa é bolsista do Fundo de Apoio à Manutenção e ao Desenvolvimento da Educação Superior (FUMDES). Mestre en Derecho Ambiental y de la Sostenibilidad pela Universidade de Alicante, Espanha. Doutorando em Juridical Science pela Delaware Law School. Endereço eletrônico: alanprovin @ hotmail.com. Endereço postal: Rodovia Carlos Braga, km 0, Salas 07 e 08, Edifício Rio Negro Center, Novo Amanhecer, Iranduba/AM, CEP 69415-000.
} 
A sustentabilidade social clama por um olhar diferenciado para a situação que as cidades se encontram.

Isso pois as cidades se tornaram o palco da grande parte desses acontecimentos, por aglutinarem em si os maiores conflitos sociais, na luta pela efetivação de direitos fundamentais.

E diversos são os estudos acerca da solução de conflitos entre direitos fundamentais, ase averiguar qual deve prevalecer em um eventual impasse.

E é por isso que se objetiva, com esse trabalho, evidenciar a sustentabilidade social como parâmetro de solução de conflitos entre direitos fundamentais na cidade, em busca de umambiente sustentável, minimizando as desigualdades. A divisão das seções acompanha os objetivos específicos, em analisar a situação dos direitos fundamentais nas cidades, recordar os ensinamentos clássicos acerca da solução de conflitos entre direitos fundamentais, e por fim, enaltecer a sustentabilidade social como meio de pacificação nas cidades.

Ainda que o presente também possa ser inserido no grupo de trabalhos de Direito Urbanístico, Cidade e Alternidade, entende-se que o foco está em reinaugurar os conceitos e dinâmicas dos institutos tradicionais do Direito, ampliando a noção de sustentabilidade para outros segmentos, na forma proposta pelo eixo de Direito e Sustentabilidade.

A pesquisa se justifica diante da necessidade de revisão dos institutos do Direito para entregar-lhes uma visão pautada na sustentabilidade, e, considerando a desigualdade social do meio ambiente urbano, para que a tomada de decisões da Administração Pública possa ser pautada em parâmetros sustentáveis, em uma visão social, quando do conflito entre direitos.

A metodologia empregada foi a bibliográfica, sob o método indutivo.

\section{A CRISE DE SUSTENTABILIDADE SOCIAL NAS CIDADES}

Os direitos fundamentais se apresentam como um resultado de uma construção teórica em um caminho conturbado, em que movimentos, guerras, rupturas políticas e econômicas, bem como diversas e bárbaras violações se fizeram presentes, e hoje são vistos como a valorização e reconhecimento da condição humana por um ordenamento jurídico.

Assim, o processo de constitucionalização se transmuta na incorporação de direitos 
subjetivos do homem em normas formalmente básicas, dando-lhes reconhecimento e garantia de respeito pelo legislador infraconstitucional, traz como consequência que a compreensão, interpretação e aplicação desses direitos os considere como normas jurídicas vinculativas, e nãoapenas como troféus de ostentação de um Estado (CANOTILHO, 2000).

São conquistas individuais e coletivas em busca de proteção de arbitrariedades estataisou de injustiças sociais, ainda que em muitos lugares ainda estejam apenas no mundo formal, sem encontrar respaldo no campo material.

E esses direitos, que comumente derivam dos direitos humanos, têm aparecido no centro dos debates ideais de civilização no último século (HARVEY, 2012).

Ao passo que a construção dos ideais dos direitos fundamentais ganhou vulto ao redordo mundo, para que pudessem alcançar um patamar democrático, inclusivo e universal, as pessoas passaram a buscar as cidades para ressignificar suas vidas, na esperança de concretização desses direitos, ainda que desconhecidos por elas. Grosso modo, em busca de vida melhor, conforto, fonte de renda e felicidade.

E é justamente por se ter conhecimento do passado manchado de sangue que os direitosfundamentais carregam e do processo histórico e natural de exclusão social, que se busca o reconhecimento das pessoas e das situações periféricas, para que as pessoas sejam vistas como singulares, dadas as suas particularidades, e recebam o tratamento dignificante correspectivo, de forma que possam se encontrar imersas no seio da dignidade da pessoa humana, fazendo parte da dinamicidade das cidades.

As cidades nunca estiveram preparadas para corresponder às expectativas dos milhões de imigrantes que as invadiram nos últimos séculos. Assim, o ideal de cidade inclusiva, plural e democrática, transformou-se em uma tragédia urbanística, palco da violência, da proliferação da pobreza e de problemas de saúde. As mudanças políticas, econômicas e sociais influenciaramdiretamente nesse contingente populacional das cidades.

Denota-se que grande parte dos programas e conceitos empregados à conjuntura dos direitos fundamentais nas cidades sempre esteve correlacionada aos ideais de propriedade individual e da lógica do mercado liberal. É necessário que os direitos, inclusive individuais, tomem um cunho coletivo, para que os resultados sejam humanizantes aos que não tiveram e ainda não têm a chance de sentir o gosto de um ambiente democrático (HARVEY, 2012).

E a urbanização de forma capitalista tende a perpetuar e destruir a cidade social, política e harmônica (HARVEY, 2012). É imperativo um novo urbanismo, uma nova forma 
de se planejar a cidade, com o cumprimento da legislação urbanística, em especial o Estatuto da Cidade e a Lei de Mobilidade Urbana, com ações que comprovadamente contribuam para o bem-estar social, de forma sustentável. Como afirma Freitas (2019), chuvas de omissão não podem continuar matando, ano após ano. Cumpre introjetar e fazer respeitar, sem procrastinação, os direitos fundamentais.

É de se relembrar que a massa mais pobre não teve o poder de decisão quando da criação das cidades, remanejando-se onde encontrassem o mínimo de possibilidade para sobrevivência.

E é imperioso que se entenda que o núcleo urbano se tornou um produto de consumo de uma alta qualidade para as mais diversas classes sociais, de ricos a pobres, nacionais a estrangeiros, em busca de negócios, turismo ou projeção de vida. A cidade sobrevive graças a esse duplo papel: lugar de consumo e consumo de lugar (LEFEBVRE, 2001).

Em pleno século XXI, a realidade urbana aparece mais como um caos e uma desordem - que sem dúvida encobre uma ordem a descobrir (LEFEBVRE, 1969). Observa-se que não somente as periferias passam por um acréscimo populacional, como também outros segmentos acompanham esse crescimento, como as redes (bancárias, comerciais, industriais) e a habitação (residências secundárias, espaços e locais de lazer), que nem sempre estão disponíveis a todos (LEFEBVRE, 2001).

Nalini (2001) exemplifica que São Paulo é um exemplo emblemático de "sacrifício ecológico em prol de se agravar o quadro de subcondições de vida subumana. Aqui se encontra um ambiente naturalmente desnaturado." Informa problemas como perda da identidade cultural, ruído, poluição, violência, falta de parques verdes.

Não por acaso que a abordagem do direito à cidade deve considerar a condição políticada cidade enquanto espaço contínuo de reivindicação, bem como a complexidade da trama social nela ocorrente (BODNAR; FREITAS; SILVA, 2016).

Em um caminho intimamente paralelo a isso, a preocupação com o meio ambiente emerge na segunda metade do século $\mathrm{XX}$, presenciando a tragédia que as cidades já se encontravam, sem conseguir evitar o que ainda as aguardava.

Historicamente, desenvolvimento e direitos fundamentais sempre existiram em planos apartados, tanto na teoria quanto na prática, isolando estes últimos de questões econômicas e sociais (UVIN, 2004). 
Daí surge o ideal de sustentabilidade e de se reconhecer o desenvolvimento sustentável como melhor caminho para obtê-la em todas as suas dimensões. O Direito Ambiental e o DireitoUrbanístico passaram a tutelar os interesses humanos em busca de uma cidade melhor.

O acréscimo populacional de maneira desenfreada e a forma que se estão desenvolvendo as cidades também vão impactar nos projetos de sustentabilidade das próximas décadas. Quanto mais pessoas existirem no planeta, mais difícil se tornará reconciliar os objetivos econômicos com cada nova vida surgindo e tendo que se adequar a isso. Quando umpaís tem um rápido crescimento populacional, também aumenta o desafio para combinar crescimento econômico, inclusão social e um meio ambiente ecologicamente equilibrado naquele ambiente (SACHS, 2015).

A insuficiência de planejamento e políticas amplas e de longo prazo acabam agravandoa crise institucional, uma vez que as pessoas e governantes ainda não conseguem pensar a solução dos problemas com premissas da sustentabilidade. Falta a percepção da real dimensãoda crise e da ameaça à garantia da vida no planeta e, por consequência, nas cidades (CRUZ; FERRER, 2015).

Não obstante as dificuldades encontradas naturalmente nas cidades, as escolhas políticas e dotações orçamentárias podem influenciar nesse processo de desenvolvimento social das cidades e, ao mesmo tempo, criar conflitos entre direitos e interesses e aumentar adesigualdade.

Ressalta-se que a razão de ser dessa abordagem não está em averiguar quem deve ser responsabilizado pelo caos que o mundo está, até porque no caso do meio ambiente (em sentidogeral) ou da pobreza, as ações ou omissões nem sempre são precisas. São coletivas e difusas (HUERTA; FUENTE, 2000).

Almeja-se analisar essa competição por sobrevivência de direitos nas cidades, em busca da sustentabilidade social.

E é nesse ponto que se pretende debruçar a atenção e pesquisa agora. Veja.

A vivência das cidades presencia inúmeros direitos em exercício ao mesmo tempo. Vida, educação, saúde, transporte, trabalho, habitação, propriedade, liberdade, segurança. Alguns à luz da dignidade da pessoa humana, outros à sombra dela. E da mesma forma, grande parte da população vê esses direitos sendo violados. E, não raro, muitos deles conflitam entre si, em busca de reconhecimento. 
Seria utopia afirmar que o Sol é para todos nas cidades. Ou, ainda, que todos os direitosencontram um lugar ao Sol.

A cidade acontece e opera como centro aglutinador de conflitos, potencialidades e demandas. Por isso é neste ambiente que os desafios são mais intensos e especialmente qualificados, pois os fatos e condutas repercutem com maior intensidade na vida das pessoas e nos ecossistemas. Da mesma forma as consequências são igualmente fortes e contundentes(BODNAR, 2015).

Além disso, as cidades de maneira geral encontram-se cada vez mais diferentes umas das outras, ainda que compartilhem de alguns problemas comuns. As demandas, as repostas, osprodutos, os níveis de tecnicidade e a capitalização diferem de um local para o outro. A organização social de cada cidade também varia de acordo com as atividades agrícolas, conhecimento e trabalho intelectual, além da questão cultural presente no local (SANTOS, 2013).

E é evidente que quando são consagrados tantos direitos como nos modelos constitucionais contemporâneos, ocorram conflitos ou dissonância com outros direitos fundamentais coexistentes no mesmo ambiente (MAY; DALY, 2015), ainda mais considerandoa forma dinâmica que as interações acontecem nas cidades.

Bobbio (2004) informa que é contraditório o ser humano sacramentar tantos direitos, em virtude da grandeza potencial que atribui a si mesmo, e pela necessidade que de se impor ditames para o alcance da democracia e a paz.

Em alguns cenários jurídicos, inclusive, os intérpretes do direito preferem dar uma conceituação mais restrita aos direitos fundamentais, justamente para diminuir a ocorrência deconflitos entre eles (SILVA, 2010).

Independente disso, Dantas (2017), relembra que por mais que algum direito seja relevante para o Direito, e por isso esteja consagrado na órbita constitucional, ele não está blindado da possibilidade de ser afastado parcial ou totalmente por outro direito que se encontre em mesma posição hierárquica. Ou seja, os direitos não são absolutos e ilimitados. Alves (2010) corrobora afirmando que como são de direitos respaldados pelo sistema constitucional, apenas em virtude de outras normas constitucionais é que poderiam sofrer restrição.

O fato de os direitos e garantias individuais e coletivas encontrarem limites nos demais direitos igualmente consagrados pela Constituição transluza a manifestação do 
princípio da relatividade ou da convivência das liberdades públicas (MORAES, 2006).

O que determina a resolução desses conflitos é a ideia de que alguma das partes da relação possui alguma situação de fato e de direito que justifique vencer. Essa situação de fato ou de direito são os direitos subjetivos atribuídos aos indivíduos sob a égide de um Estado Democrático de Direito. (MASTRODI, 2014)

Ainda assim, como escolher ou optar, quais direitos, liberdades ou interesses de cunhofundamental devem prevalecer em eventual conflito?

Nesse sentido, muitos são os estudos e as teorias criadas para tentar desenvolver esse impasse. Esses estudos já se encontram suficientemente aprofundados em diversas obras, por isso sua narrativa será abreviada, para que se possa prosseguir com o que se pretende aduzir.

\section{MÉTODOS DE SOLUÇÃo DE CONFLITOS ENTRE DIREITOS FUNDAMENTAIS}

Quando duas normas que se encontram em igual hierarquia entram em colisão, é natural que não se possa fornecer uma solução padrão ao problema. Assim, cabe ao intérprete criar o direito aplicável ao caso (BARROSO, 2005). Isso porque os critérios utilizados para solução dos conflitos não estão no texto jurídico. (ALVES, 2010)

E um dos pontos principais neste debate acerca da interpretação constitucional de direitos fundamentais, é o papel do balanceamento, ponderação ou sopesamento de interessese direitos (ALEXY, 2006).

As possibilidades de ponderação não decorrem de enunciados normativos, mas principalmente da racionalidade e capacidade de justificação, orientando um caminho em busca de uma solução mais correta para um problema concreto, ainda que, ao final, não acarrete o sucesso da decisão (ALVES, 2010).

Silva (2010) afirma que o recurso do sopesamento tem sido alvo de inúmeras críticas, as quais apontam a irracionalidade do meio.

O sopesamento ganha relevo na Teoria dos Direitos Fundamentais de Alexy (2017), pela qual as normas se dividem em regras e princípios. As regras, de caráter mandamental, são normas que, caso válidas, devem ser cumpridas, nem mais nem menos, pois possuem determinações no âmbito daquilo que é fático e juridicamente possível. Dworkin (1978), no 
mesmo sentido, informa que se a regra é válida, a resposta que ela fornece deve ser aceita.

Dessa forma, as regras não admitem sopesamento, uma vez que apenas uma delas é que deve ser aplicada ao caso. Não existiriam duas regras contraditórias aplicáveis ao mesmo tempo. O conflito seria então aparente.

E por muito tempo sempre foi pregado que regras valem tudo ou nada, não sendo passíveis de ponderação, como acontece com os princípios. Em situações excepcionais, entretanto, a derrotabilidade deve ser invocada para afastar regras de casos concretos, em cuja aplicação estas não cumpram com a finalidade constitucional, não podendo elas formarem jurisprudência. Esse é um dos pontos que o neoconstitucionalismo avança, afastando a impossibilidade de ponderação daquilo que não pode, por questão de justiça, ser aplicado ao caso concreto (MOREIRA, 2008).

Isso pois nenhum legislador, por mais sábio ou cuidadoso que pudesse ser, conseguiria antecipar toda a gama de exceções pela própria lei. Dessa forma, nem todos os casos seriam julgados pelas regras aplicáveis. A justiça deve superar a rigidez esperada das normas em casosexcepcionais (D’ALMEIDA, 2015).

A boa tomada de decisão abandona a antiquada e desidiosa interpretação estrita das regras, tentando extrair os maiores benefícios, direitos e efeitos das normas (JUAREZ, 2019).

É nesse sentido que, após as atrocidades cometidas na Alemanha, em que a ascensão do regime nazista levou ao extermínio de judeus, negros, homossexuais e ciganos com base emleis vigentes, em regras segregacionistas apresentadas inclusive na defesa dos condenados no Julgamento de Nuremberg, passou-se a tecer severas críticas à concepção de regras absolutas, sob pena de se cometer novas barbáries em nome da lei.

Dessa forma, "a normatividade dos princípios passa a ser uma necessidade para impedir a repetição de um passado do qual só não se quer esquecer para que não volte a se repetir" (DANTAS, 2017).

É cediça a importância de aplicação de valores jurídicos que superem a rigidez de umtexto positivado. O Direito não se limita a reproduzir o que está escrito ao mundo fático, pois assim estar-se-ia correndo o risco de esvaziar o conteúdo da hermenêutica enquanto da manutenção dos direitos básicos.

Por esse motivo que surgem os princípios, com profunda carga jurídica, penetrando nos ordenamentos jurídicos em ordem nacional e global, para orientar a atividade humana, 
quer esteja à frente da direção Estado ou na condição de cidadão, de maneira a superar a normatividade positivada.

Os princípios se tornam, assim, o oxigênio constitucional dessa época do póspositivismo, sendo que, graças a eles, os sistemas auferem a valoração de sua ordem normativa. Enquanto as regras vigem, os princípios valem, governam a Constituição, o regime democrático, a ordem jurídica. Não são apenas a lei, mas o Direito em toda a sua extensão, substancialidade, plenitude e abrangência (BONAVIDES, 2004).

Os princípios são ordenações que se esparramam e magnetizam os sistemas das normas, nos quais os valores e bens constitucionais passam a trilhar caminhos juntos (SILVA, 2016). São normas que servem de razões de dever-ser, ordenando que algo seja realizado na maior medida dentro das possibilidades (jurídicas e fáticas) existentes, consideradas então mandamentos de otimização (ALEXY, 2017).

Como mandatos de otimização, os princípios podem ser cumpridos em diversos graus, a depender das possibilidades fáticas e jurídicas (PADILHA, 2006).

Dworkin (1978) afirma que princípio é um padrão a ser observado, pelo fato de promover justiça ou equidade ou alguma outra dimensão da moralidade, e não necessariamente porque com isso será possível promover ou assegurar uma situação econômica, política ou social desejável.

E os desdobramentos decorrentes da aplicação dos princípios são também variados.

E é por isso que os princípios também são usados no sentido de marco inicial da construção dos diversos ramos do Direito e como indicadores da legislação e da sua aplicação em determinado campo específico (BRANDÃO, 2016).

Isso pois uma interpretação apropriada dos direitos constitucionais afasta o absolutismo de cada um singularmente, de maneira a haver um respeito saudável em direitos que compitam pela preponderância em determinado momento, e aceitando limites a certos direitos, na proporção que lhes seja cabível in casu (MAY; DALY, 2015).

E nessa toada, a proporcionalidade assume importante função na ponderação de valores e direitos, tentando aliar a justiça e a segurança jurídica, com adequação da decisão tomada (ALVES, 2010).

Apesar de ser um critério para a solução de conflitos entre direitos, a proporcionalidadenão se trata propriamente de um princípio, mas de uma máxima a sempre ser observada. Isso pois em um Estado de Direito, em que a democracia e a dignidade da 
pessoa humana imperem, não são admitidas hipóteses em que a proporcionalidade não possa ser aplicada como vetor interpretativo (DANTAS, 2017).

Importante aduzir que a proporcionalidade em si não é um critério para resolver os conflitos reais, mas sim para justificar e legitimar as decisões tomadas acerca dessas colisões (MASTRODI, 2014).

Assim como o princípio da precaução e os demais princípios de direito ambiental também pode estabelecer diretrizes acerca das possíveis escolhas a serem tomadas.

Certo é que, qualquer forma de resolução de conflitos entre direitos que se leve a cabo,deve-se dispender atenção especial à teoria da proteção do núcleo essencial. Trata-se de um limite à possibilidade de limitar direitos (ALVES, 2010).

Isso pois deve-se estabelecer até que ponto os direitos fundamentais podem ser limitados, para que não sejam desvirtuados de sua essência, em homenagem à teoria dos limites dos limites, que "visa a designar os diversos obstáculos normativos que restringem a possibilidade de o poder público limitar os direitos fundamentais" (DEMARCHI; FERNANDES, 2015).

Por esse motivo, antes de se optar por algum dos direitos envolvidos no conflito, é necessário que se coordene e combine os bens jurídicos em conflito, "evitando o sacrifício totalde uns em relação aos outros, realizando uma redução proporcional do âmbito de cada qual". Éo princípio da concordância prática ou da harmonização que é trazido à baila para se efetivar ao máximo o significado da norma em busca da harmonia do texto constitucional com sua finalidade (MORAES, 2006).

É uma forma de não se levar ao máximo do tudo ou nada, encontrando uma harmoniaentre os interesses, e somente em caso de não ser possível que se pondere e deixe de aplicar umou outro (DANTAS, 2017).

Ademais, a dignidade da pessoa humana também norteia a interpretação nas demandas envolvendo os direitos fundamentais. Ela torna-se uma cláusula de barreira, estabelecendo um “território proibido”, em que determinadas práticas não são admitidas, em que o Estado não pode intervir, mas também deve assegurar a proteção da pessoa contra terceiros (SARLET, 2015).

Alves (2010) explica que apesar de a Constituição não ter explicitado preferência entreos direitos, elevou a status de cláusula pétreas alguns valores vinculados à dignidade da pessoa humana, demonstrando que possuem peculiar relevo na ordem jurídica. Assim, em 
eventual ponderação, os valores vinculados à dignidade da pessoa humana devem ser levados em consideração, em homenagem à “inequívoca expressão desse princípio".

Ainda que reconhecendo a importância desse conjunto interpretativo que, direta ou indiretamente, a presente pesquisa não pretende se aprofundar nas teorias clássicas de resoluçãode conflitos entre direitos, mas analisá-los sob um outro viés.

A este ponto, é de se reforçar que é inócuo afirmar que exista apenas uma solução aceitável e legítima para cada caso, contudo, deve-se buscar aquela que considerando as situações fáticas e jurídicas envolvidas, garanta com maior primazia o bloco de princípios, desejos, objetivos e direitos constitucionais (FREITAS, 2019).

E os conflitos reais, caso não houvesse a tutela estatal, seriam resolvidos, muito provavelmente, pela autotutela. Assim, devem ser decididos com base em normas jurídicas e nos valores sociais que dão conteúdo e sentido a elas. E apesar de formalmente iguais, as normasnão tutelam interesses iguais em termos materiais (MASTRODI, 2014).

\section{A SUSTENTABILIDAdE SOCIAL COMO PARÂMETRO DE SOLUÇÃO DE CONFLITOS NAS CIDADES}

Realçados os ensinamentos da teoria clássica da solução de conflitos, parte-se para compreender como a sustentabilidade social pode ser parâmetro de solução desses conflitos.

Diante da consideração de diversos princípios com poder de "desempate" entre direitos, afirma-se que a sustentabilidade também deve ser considerada como um princípio constitucional de interpretação, à medida que demanda a concretização de uma sociedade solidária, inclusiva, durável e equânime, ambientalmente limpa, inovadora, ética e eficiente, buscando sempre o bem-estar. Ao mesmo tempo, não pode ser considerada como um princípioabstrato, elusivo ou de observância facultativa: ela deve vincular plenamente, sendo inconciliável com modelos que descumpram a função socioambiental de bens e serviços. É umprincípio que visa resguardar o direito ao futuro (FREITAS, 2019).

A sustentabilidade social, nesse diapasão, não admite o modelo de desenvolvimento excludente, insensível e injusto, em que a luta pela sobrevivência seria limitada a poucos integrantes dos grupos oligárquicos, de maneira indiferente aos demais seres vivos (FREITAS, 2019).

A sustentabilidade social obriga a assegurar a inclusão de todos os grupos 
populacionais em uma sociedade urbana para garantir o acesso à moradia e ao solo, bem como o direito ao trabalho, fator básico para conseguir uma melhora na qualidade de vida das pessoas(SOLÉ, 2002).

Sociedades em que a desigualdade reina estão mais propensas a conflitos sociais, e, por sua vez, a serem socialmente insustentáveis (JACOBS, 2016).

É nesse contexto que a própria interpretação constitucional também sofre modificações. Isso pois, na medida do possível, essa passa reconhecer que não há um único caminho possível para uma decisão democrática (SANTOS, 2006). Não só reconhecer, mas também evitar essa perspectiva.

Há de se abraçar a ideia de que a força da norma jurídica depende mais do seu conteúdo, se adequando aos valores e interesses sociais que estruturam atualmente a sociedade, do que da sua forma, que é adequada ao sistema jurídico (MASTRODI, 2014).

Eros Grau afirma que nem mesmo a Sexta Sinfonia de Beethoven possui uma única interpretação correta, não podendo os casos jurídicos assim o terem, ainda que o intérprete esteja vinculado a um sistema jurídico (GRAU, 2009).

Dessa forma, considerando os vértices jurídicos constitucionais que consideram o meio ambiente saudável em todas as suas dimensões como direito fundamental de todos, reconhecendo a necessidade de se encontrar meios sustentáveis para isso, conjugando com o histórico das cidades, da pobreza e da exclusão social, a tese que pretende se firmar é que a sustentabilidade social, enquanto princípio constitucional, também é parâmetro na solução de conflitos entre direitos fundamentais nas cidades.

Ou seja, diante de conflitos entre direitos fundamentais, deve-se apurar, dentre as possibilidades, o que atende com maior proximidade os ditames da sustentabilidade social.

Trata-se de homenagear as formas de interpretação da Constituição, garantindo a unidade, harmonia e máxima eficácia das disposições constitucionais. De dar sustento ao povocalejado das cidades.

Considerando que os direitos cristalizam normas jurídicas, valores ou interesses considerados importantes pela sociedade que os positivou, e que representam, conforme aludido, os interesses de determinada época e que, naturalmente, ao longo do constitucionalismo, pessoas com posições sociais predominantes fizeram positivar os seus interesses para aplicar a toda a sociedade indistintamente, de forma que a desigualdade passoua ser vista como algo bom e justo, ainda que a sua erradicação esteja simbolicamente 
constitucionalizada, é chegada a hora de dar um novo olhar a esses conflitos entre direitos. O olhar da sustentabilidade social, a fim de valorizar a coletividade ignorada secularmente pelo sistema capitalista (MASTRODI, 2014).

Não é de se ignorar que a imprecisão do conceito de desenvolvimento sustentável, ou da própria sustentabilidade, torna difícil a criação de rumos certos a serem tomados. E essa dificuldade surge de duas principais fontes. A uma, pode-se afirmar que é difícil tornar operacional um conceito que não há consenso sobre ele. A cada palavra que se levante ao conceituar esses termos, outras tantas perguntas são igualmente criadas. Há uma infinidade deinterpretações ao termo. A duas, há uma preocupação política com a falta de claridade das definições do que é sustentável ou do que é promover um desenvolvimento sustentável. Assim,os limites ficam imprecisos, vagos (JACOBS, 2016).

É possível dizer que o próprio conceito de sustentabilidade sofre mutações no decorrer do tempo. É um termo aberto, permeável, ideologizado, subjetivo e relacional. O que é considerado sustentável num período de profunda crise econômica pode não ser num período de fartura. Em muitos casos, é até mais indicado adotar-se uma dimensão conceitual negativa, ou seja, muitas vezes é mais fácil identificar as situações de insustentabilidade (BODNAR; FREITAS; SILVA, 2016).

Como ponto de partida, acredita-se que as escolhas pautadas na sustentabilidade social devem construir inclusão, a nível individual, de grupos e da sociedade, prover de dignidade humana e capacidade política, tornando essas pessoas parte do processo político e criar a capacidade de aprendizado em cada nível, para que possam colaborar em todo o processo(LARSEN, 2009).

Deve-se identificar com que problemas cada localidade está lidando, e de que forma os recursos e tecnologias podem ajudar nesse processo. Talvez sejam necessários testes e errospara se chegar a um denominador sustentável (ROGERS; JALAL; BOYD, 2008).

Nesse sentido, tolhem-se ensinamentos de Cruz e Ferrer (2015), que relembram quea sustentabilidade é um processo mediante o qual se tenta construir uma cidade global capaz de se perpetuar indefinidamente no tempo em condições que garantam a dignidade humana. Apósisso, quando atingido o objetivo de construir essa sociedade, será sustentável aquilo que contribua para esse processo, e, da mesma forma, insustentável o que se afasta dele.

Freitas (2019) aduz que o olhar para o desenvolvimento sustentável deve ser obtido considerando suas determinações nucleares, de cunho ético e institucional, quais sejam: a) 
compreensão de que decorre de mandamentos constitucionais de assegurar ambiente propício ao bem-estar às gerações presentes e futuras, monitorado por indicadores qualitativos, com a menor subjetivação possível; b) responsabilização do Estado pela prevenção e pela precaução, de forma que este se antecipe aos eventos danosos; c) controle das escolhas públicas e privadas na elaboração de condutas precisas e sustentáveis; d) foco em ter a sustentabilidade como norteadora do desenvolvimento, e não o contrário.

E a população local deve ser ouvida, a fim de se averiguar se é uma sociedade consumista ou engajada com causas sociais, se está resistente à globalização, ou integrada nestemeio. Por exemplo: as pessoas andariam de bicicleta se tivessem ciclovias? (ROGERS; JALAL; BOYD, 2008). Em alguns lugares, o próprio relevo ou a condição cultural não permitiria a adoção com tamanha facilidade desse meio de transporte.

Não obstante, Holland (2002) relembra que há um critério muito subjetivo em tentaralcançar a felicidade ou o bem-estar da população. Ainda que se promova tudo o que estiver aoalcance da Administração Pública, há diversas circunstâncias que não podem ser antecipadas ou supridas pelo poder público, como a disposição psicológica individual, circunstâncias culturais (as quais incluem a subjetividade do que é qualidade de vida) e eventos imprevisíveis.Isso porque nem todas as pessoas podem concordar com o que lhes é concebido ou atribuído como "bom", com base apenas em argumentos racionais (SHUMPETER, 2003). Há um sentimento de pertencimento muito grande em algumas realidades, ainda que absurdas a outros olhos.

Sem embargo, toda teoria, está sujeita a ter pontos fortes e imperfeições quando da sua aplicação. A própria teoria dos direitos fundamentais possui inegáveis qualidades, mas também uma série de problemas, inerentes à sua teoria ou decorrentes da sua aplicação (MASTRODI,2014).

Ainda assim, ciente de que não é possível impor a felicidade, tampouco o conceito doque é bom a uma imensidão de pessoas singulares entre si, aceita-se o desafio de, seguindo as premissas da sustentabilidade social, chegar o mais próximo possível disso.

\section{CONSIDERAÇÕES FINAIS}

Diante de todo o exposto, pôde-se perceber como as nuances da sustentabilidade podem contribuir para a construção de um ambiente urbano inclusivo. 
Isso pois historicamente as cidades foram construídas ao descaso, por aqueles que detinham poder, excluindo-se qualquer participação aos meios de dignificação do restante da sociedade.

As favelas e regiões periféricas são um retrato do descaso secular para as causas sociais. Ainda que se viva sob um Regime Democrático Constitucional, é árduo e longo o caminho ainda em busca da efetivação de todos os direitos fundamentais.

Não obstante, os métodos de resolução de impasses entre direitos fundamentais também carecem de um olhar social sobre as causas que lhe dão suporte, sob o risco de se tornara letra fria da lei uma ditadura de regras injustas.

Apesar de a sustentabilidade surgir como um fim a ser alcançado, certo é que tambémpode ser utilizada como um meio, e é também um parâmetro para se poder prosseguir quando se está diante de direitos de igual patamar hierárquico.

Sob o viés social, tem-se uma reparação histórica dos erros cometidos sob as normas do mercado opressor, oportunizando a todos os citadinos o direito à cidade, a oportunidade de alcançar a dignidade da pessoa humana e a possibilidade de se sentirem seres de valor, em umasociedade que sempre lhes negou a titularização de direitos.

\section{REFERÊNCIAS}

ALEXY, Robert. Discourse Theory and Fundamental Rights. In: MENÉNDEZ, Agustín José;ERIKSEN, Erik Oddvar (Org.). Arguing Fundamental Rights. Dordrecht: Springer, 2006.

ALEXY, Robert. Teoria dos Direitos Fundamentais. Trad. Virgílio Afonso da Silva. 2a. ed.São Paulo: Malheiros, 2017.

ALVES, Nadia Castro. Colisão de direitos fundamentais e ponderação. In: Meritum, Belo Horizonte, v. 5, n. 1, p. 25-48, jan./jun.2010.

BARROSO, Luís Roberto. Neoconstitucionalismo e constitucionalização do direito. In:

Revista de Direito Administrativo, Rio de Janeiro, n. 240, abr/jun 2005. p. 1-42.

Disponível em: < http://bibliotecadigital.fgv.br/ojs/index.php/rda/article/view/43618>. Acesso em 09 jun.2018.

BOBBIO, Norberto. A Era dos Direitos. Trad. Carlos Nelson Coutinho. Rio de Janeiro: 
Elsevier, 2004.

BODNAR, Roberta Terezinha Uvo; BODNAR; Zenildo. A Epistemologia Interdisciplinar do Direito à Cidade. In: ENCONTRO NACIONALD O CONPEDI UFMG/FUMEC/DOM HELDER CÂMARA, XXIV, Florianópolis: CONPEDI, 2015.

BODNAR, Zenildo; FREITAS, Vladimir Passos de; SILVA, Kaira Cristina. A Epistemologia Interdisciplinar da Sustentabilidade: por uma ecologia integral para a sustentação da casa comum. In: Revista Brasileira de Direito, 12(2): p. 59-70, jul.-dez. 2016.

BONAVIDES, Paulo. Curso de Direito Constitucional. 15a. ed. São Paulo: Malheiros, 2004. BRANDÃO, Paulo de Tarso. Princípios Constitucionais, Desenvolvimento Urbano e Meio Ambiente. In: SOUZA, Maria Claudia Antunes; JACOBSEN; Gilson. Direito, Desenvolvimento Urbano e Meio Ambiente. Itajaí: UNIVALI, 2016.

CANOTIlHO, José Joaquim Gomes. Direito Constitucional e Teoria da Constituição. Coimbra: Almedina, 7a. ed., 2000.

CRUZ, Paulo Márcio; FERRER, Gabriel Real. Direito, Sustentabilidade e a Premissa Tecnológica como Ampliação de seus Fundamentos. In: Revista Sequência, Florianópolis, v. 36, n. 71, p. 240-278, dez. 2015. Disponível em:

<https://periodicos.ufsc.br/index.php/sequencia>. Acesso em: 22 jan. 2016.

D’ALMEIDA, Luís Duarte. Allowing for Exceptions: a theory of defences and defeasibility in law. Oxford: Oxford University Press, 2015.

DANTAS, Marcelo Buzaglo. Direito Ambiental de Conflitos: o direito ao meio ambiente ecologicamente equilibrado e os casos de colisão com outros direitos fundamentais. 2a. ed. Riode Janeiro: Lumen Juris, 2017.

DEMARCHI, Clóvis. FERNANDES, Fernanda Sell de Souto Goulart. Teoria dos Limites: análise da limitação à restrição dos direitos fundamentais no direito brasileiro. In: Revista Brasileira de Direitos e Garantias Fundamentais. Belo Horizonte, v. 1, n. 2, p.73-89, jul/dez2015.

DWORKIN, Ronald. Taking Rights Seriously. Cambridge: Harvard University Press, 1978.

FREITAS, Juarez. Sustentabilidade: direito ao futuro. 4a. ed. Belo Horizonte: Fórum, 2019. 
GRAU, EROS. Ensaio e discurso sobre a interpretação/aplicação do direito. 5a. ed. São Paulo: Malheiros, 2009.

HARVEY, David. Rebel cities: from the right to the city to the urban revolution. New York - London: Verso, 2012

HOLLAND, Alan. Sustainability: should we start from here? In: DOBSON, Andrew. Fairnessand Futurity: essays on environmeal sustainability and social justice. New York: Oxford University Press, 2002.

HUERTA, R. Huerta; FUENTE, C. Huerta Izar de la. Tratato de Derecho Ambiental. Tomo I. Barcelona (España): Bosch, 2000.

JACOBS, Michael. Sustainable Development as a Contested Concept. In: DOBSON, Andrew. Fairness and Futurity: essays on environmeal sustainability and social justice. New York: Oxford University Press, 2002.

LARSEN, Gary L. An Inquiry Into the Theoretical Basis of Sustainability: ten propositions. In: DILlARD, Jesse. DUJON, Veronica. KING, Mary C. Understanding the Social Dimension of Sustainability. New York: Routledge, 2009

LEFEBVRE, Henri. Da ciência à estratégia urbana. Trad. Pedro Henrique Denski e Sérgio Martins Paris: Utopie, n. 2 e 3. p. 57-86, mai. 1969.

LEFEBVRE, Henri. O Direito à Cidade. Trad. Rubens Eduardo Frias. São Paulo: Centauro, 2001.

MASTRODI, Josué. Ponderação de direitos e proporcionalidade das decisões judiciais. In:

DireitoGV, São Paulo, jul./dez. 2014.

MAY, James R.; DALY, Erin. Global Environmental Constitutionalism. Cambridge: Cambridge University Press, 2015.

MORAES, Alexandre de. Direito Constitucional. 32a. ed. São Paulo: Atlas, 2006.

MOREIRA, Eduardo Ribeiro. Neoconstitucionalismo e teoria da interpretação. In: Revista daEMERJ, Rio de Janeiro, v. 11, n. 43, 2008. p. 247-268. Disponível em:

<http://www.emerj.tjrj.jus.br/revistaemerj_online/edicoes/revista43/Revista43_247.pdf >.Acesso em 07 jun. 2018. 
NALINI, José Renato. Direitos Que a Cidade Esqueceu. São Paulo: Revista dos Tribunais, 2011.

PADILHA, Norma Sueli. Colisão de Direitos Metaindividuais e a Decisão Judicial. PortoAlegre: Sergio Antonio Fabris Editor, 2006.

ROGERS, Peter P. JALAL, Kasi F. BOYD, John A. An Introduction to Sustainable Development. New York City: Earthscan, 2008.

SACHS, Jeffrey D. The Age of Sustainable Development. New York: Columbia UniversityPress, 2015.

SANTOS, Gustavo Ferreira. Neoconstitucionalismo e democracia. In: Revista de informaçãolegislativa, Brasília, a. 43, n. 2006. p. 45-55. Disponível em:

<http://www2.senado.leg.br/bdsf/bitstream/handle/id/93282/Santos\%20Gustavo.pdf?sequence

>. Acesso em 08 jun. 2018.

SANTOS, Milton. A Urbanização Brasileira. São Paulo: Editora da Universidade de SãoPaulo, 2013.

SARLET, Ingo Wolfgang. Dignidade (da Pessoa) Humana e Direitos Fundamentais naConstituição Federal de 1988. 10a. ed. Porto Alegre: Livraria do Advogado, 2015.

SOLÉ, Juli Ponce. Poder Local y Guetos Urbanos. Madrid (España): Fundació Carles PI iSunyer, 2002.

SHUMPETER, Joseph A. Capitalism, Socialism and Democracy. New York City: Routledge,2003.

SILVA, José Afonso da. Curso de Direito Constitucional Positivo. 39a. ed. São Paulo:Malheiros, 2016.

SILVA, Virgílio Afonso da. Colisões de direitos fundamentais entre ordem nacional e ordem transnacional. In: NEVES, Marcelo. Transnacionalidade do direito: novas perspectivas dosconflitos entre ordens jurídicas, São Paulo: Quartier Latin, 2010.

UVIN, Peter. Human Rights and Development. Bloomfield: Kumarian Press, 2004. 